\title{
LOS ROLES DE GÉNERO EN LA MÚSICA INFANTIL DE LA PLATAFORMA DIGITAL YOUTUBE
}

\section{GENDER ROLES IN CHILDREN'S MUSIC OF THE YOUTUBE DIGITAL PLATFORM}

Javier Juárez Rodríguez ${ }^{1}$. Universidad de Medellín. Colombia. jiuarez@udem.edu.co

\section{RESUMEN}

El presente artículo analiza la representación de los roles de género reproducidos en los tres principales canales de música infantil de YOUTUBE: El Reino Infantil, La granja de Zenón y Toy Cantando. Los tres cuentan con más 40 millones de suscriptores, jugando un papel importante en el proceso de socialización y consolidación de imaginarios entre los más pequeños. El trabajo tiene como objetivo estudiar un total de 30 videos/canciones, los diez más vistos de cada canal, aplicando para ello la perspectiva de género de forma transversal en su análisis, priorizando su estudio en torno a tres áreas o campos de análisis: 1. Estudio de los roles protagónicos 2 . Representación de los modelos de feminidad y masculinidad 3. Análisis del universo simbólico y la interrelación de los personajes. El trabajo aborda el papel de la música como un agente socializador capaz de plasmar e incluso fortalecer los valores de una sociedad determinada, a la vez que promover cambios y replantear la validez del sistema y sus principios. Uno de los objetivos de la investigación se centra en analizar tanto las letras de las canciones como su representación audiovisual en los videos seleccionados, llevando a cabo, para ello, un análisis sobre las representaciones y los roles de género en los personajes protagónicos de las historias.

PALABRAS CLAVE: educación Infantil; socialización; género; Música.

\section{ABSTRACT}

The present article analyzes the representation of the gender roles reproduced in the three main channels of children's music of YOUTUBE: El Reino Infantil, La granja de Zenón y Toy Cantando. The three have more than 40 million subscribers, playing an important role in the process of socialization and consolidation of imaginaries among the smallest. The work analyzes a total of 30 videos / songs, the ten most watched of each channel, and applies the gender perspective in a transversal way in its analysis, prioritizing its study around three areas or fields of analysis: 1 . Analysis of the leading roles 2 . Representation of the models of femininity and masculinity 3 . Study of the symbolic universe and the interrelation of the characters. The work addresses the role of music as a socializing agent capable of capturing and even strengthening the values of a given society, while promoting changes and rethinking the validity of the

\footnotetext{
1Javier Juárez Rodríguez: Doctor en Periodismo por la Universidad Complutense de Madrid. Profesor Investigador de la Facultad de Comunicación de la Universidad de Medellín (Colombia). Integrante del grupo GRECO de investigación.
} 
system and its principles. One of the objectives of the research is to analyze both the lyrics of the songs and their audiovisual representation in the selected videos, and carrying out, for this, a first analysis on the representations and gender roles in the main characters of the stories.

KEYWORDS: early childhood education; socialization; gender; Music.

\section{Cómo citar el artículo:}

Juárez Rodríguez, J. (2020). Los roles de género en la música infantil de la plataforma digital YouTube. Revista de Ciencias de la Comunicación e Información, 25(1), 19-37.

doi: http://doi.org/10.35742/rcci.2020.25(1).19-37

\section{INTRODUCCIÓN}

A pesar de los logros sociales y legislativos conseguidos a nivel mundial a lo largo de los últimos años en materia de políticas activas para promover y garantizar la igualdad de género y concienciar y formar a una ciudadanía comprometida con una sociedad libre de discriminación por razones de género, el patriarcado, entendido como una organización social asimétrica en la que el hombre/varón tiene el poder y es la medida y la referencia del resto de cosas y personas (Marañón, 2018, p. 33), sigue estando presente en nuestro día a día, a veces de forma explícita y en muchas otras de forma tan sutil que acaba por normalizarse y aceptarse. Su consolidación a lo largo de la historia le ha permitido mutar para perpetuarse por lo que, a pesar de los citados avances y de que "el discurso político y de los medios de comunicación hace creer que ya se ha logrado la igualdad", la realidad es que, en muchos aspectos, la sociedad "está retrocediendo, en lugar de avanzando, en materia de igualdad" (Tajahuerce, 2018, p. 30).

Aunque es cierto que las democracias han consumado una tendencia a fortalecer "sociedades formalmente igualitarias" con "políticas activas de igualdad", la realidad, como señala la filósofa Ana de Miguel (2019), evidencia que los valores patriarcales siguen presentes y se reflejan con una especial virulencia en "el mundo de la creación, el de los medios de comunicación y el consumo de masas" (pp. 23-24). Una de las estrategias empleadas por el patriarcado para perpetuarse es a través del control de la comunicación y los agentes socializadores (Varela, 2018, p.159), jugando el lenguaje un papel central. En este sentido, unos los campos primarios que reflejan los lenguajes morales (Cortina, 2007) de una sociedad determinada es la música en general y la infantil en particular. Tal y como advierte la investigadora Anna M. Fernández (2006) las canciones infantiles "no son algo inocuo" sino que recrean una narrativa que "reproduce, o a veces cambia, el discurso hegemónico cultural de una sociedad" ( $p$. 37). De este modo, sus letras condesan representaciones simbólicas que "reflejan la construcción de los valores y costumbres" que son asimilados por los más pequeños, quienes construyen "el mundo a través de las letras infantiles que desde edad temprana reproducen" (Coleto, 2015, p. 20). La música infantil, lejos de ser un elemento carente de trasfondo, puede ser "un recurso pedagógico que trascienda su función meramente estética o de esparcimiento" (Martínez; Colarte, 2013, p. 7). Es precisamente este 
poder transformador (o no) y constructor de modelos, valores e imaginarios lo que hace de la música dirigida al público infantil un objeto de análisis prioritario, más aún desde una perspectiva analítica con perspectiva de género, ya que, tal y como señala la investigadora mexicana Marta Lamas (2007), la "subordinación de género se construye desde la infancia" (p. 135), constituyéndose la música infantil como un agente primario en este proceso de socialización, construyendo desde la primera infancia modelos sobre las relaciones de género (Fernández, 2006, p. 38).

Las nuevas tecnologías han convertido la música infantil en un elemento presente a diario en millones de familias, hasta el punto de que algunos teóricos llegan a denominar a las plataformas digitales como el nuevo chupete electrónico (Montaño, 2019). A pesar de que asociaciones de pediatría siguen alertando sobre los efectos nocivos del uso excesivo de dispositivos móviles, sobre todo en los bebés, lo cierto es que cada vez son más quienes optan por las nuevas tecnologías como parte de los procesos formativos, educativos y lúdicos de los más pequeños. La música es, sin duda, una pieza fundamental para el desarrollo cognitivo y psico-afectivo de niños y niñas, por lo que esta investigación cobra, si cabe, mayor relevancia de cara a analizar de forma plural y detallada qué modelos, mensajes e imaginarios se está trasladando a los millones de niños y niñas que consumen a diario este tipo de música. Su consolidación como "recurso pedagógico motivador" (Martínez; Colarte, 2013, p. 5) hace necesario su análisis y su abordaje desde un enfoque con sensibilidad de género que profundice en los modelos propuestos en las canciones infantiles más reproducidas en la actualidad para ahondar y reflexionar si a través de ellas se está fomentando en los procesos de socialización el fortalecimiento de valores y/o pensamientos fundamentados en el machismo, el cual debemos entenderlo como una forma de organización de las relaciones entre los géneros que condiciona el orden social establecido (Marañón, 2018, p. 33). En este sentido, la plataforma digital YOUTUBE se ha convertido en referente para millones de familias a nivel mundial para que sus hijos e hijas escuchen música creada específicamente para un público infantil. Son numerosos los canales destinados única y exclusivamente a este fin. El top diez de los más exitosos, visitados y seguidos en relación a su número de suscriptores está compuesto por:

1. Reino Infantil (20.6 millones)

2. La granja de Zenón (12.7 millones)

3. Toy cantando (11.2 millones)

4. Gallinita Pintadita (7.4 millones)

5. El Reino a Jugar (6.9 millones)

6. ChuchuTV (5.1 TV)

7. Cleo y Cuquín (3.8 millones)

8. Pica Pica Oficial (3.5 millones)

9. Cartoon Studio (3.2 millones)

10. Bíper y sus amigos (3.2 millones)

11. Cantajuego (3.1 millones)

\section{OBJETIVOS}

El trabajo investigativo, desarrollado entre los meses de marzo y mayo de 2019, centra por tanto su campo de estudio en la música infantil reproducida por los principales canales que encabezan la lista ya adelantada, y dentro de la misma ha 
focalizado su análisis en las canciones y contenidos de las tres plataformas más exitosas de las ya mencionadas, es decir: Reino Infantil, La granja de Zenón y Toy Cantando. La metodología empleada opta por un enfoque mixto, donde los aportes conseguidos a través de la recolección de datos estadísticos han sido, a su vez, analizados desde una óptica cualitativa. En este sentido, se sometieron a estudio los diez videos/canciones con mayores visualizaciones de cada uno de estos canales, aplicando para ello de forma transversal la perspectiva de género para analizar tanto el lenguaje verbal, es decir, las letras de las canciones, como el no verbal, es decir, cómo son representadas estas canciones en el aspecto visual, estudiando los personajes que aparecen en ellas, sus representaciones, las formas de relacionarse entre ellos, así como los roles asignados aplicando para ello un análisis con perspectiva de género con el objetivo de detectar los modelos y los estímulos que están recibiendo los más jóvenes a través de estas 30 canciones/videos.

Como señalábamos al inicio del presente apartado, no cabe duda de que el siglo XX ha estado marcado por la consecución de grandes avances políticos, legislativos y sociales en materia de no discriminación por razones de género, siendo la comunicación un eje básico para lograr consumar estos logros. Agentes culturales que en un primer momento fueron minusvalorados, han evidenciado tener una enorme capacidad de influencia y permeabilidad en la sociedad. Áreas como el cine, la literatura o la música han jugado y juegan un papel fundamental como agentes socializadores y creadores de imaginarios colectivos. En esta búsqueda de cambio social en pos de una sociedad más libre e inclusiva ante la diversidad, la educación juega un papel vital, por lo que niños, niñas y población juvenil suponen, o deberían suponer, un foco prioritario a la hora de analizar qué mensajes están recibiendo, quiénes son sus referentes y qué imaginarios y valores se están conformando a través de sus fuentes de influencia y constructos sociales. Como señala la investigadora Iria Marañón (2018), las diferentes expresiones culturales interpretan el mundo en el que vivimos e instalan "en nuestro imaginario colectivo los clichés" ( $p$. 52). En este campo, sin duda la música es un agente con una enorme capacidad de influencia y, en el caso dela población infantil, capacidad de construir imaginarios mediante los mensajes que traslada a su público potencial. Por todo ello, este proyecto aborda esta realidad muchas veces menospreciada y muy poco, por no decir nada, investigada en profundidad.

Los videos de canciones infantiles, sus letras, melodías y representaciones, quedan grabadas a diario en millones de niños y niñas que asumen sus propuestas como un todo incuestionable, es decir, a través de su visualización se acomodan e interiorizan como parte de su aprendizaje (Martínez; Colarte, 2013) y quedan instaladas en las bases de sus constructos sociales, por ello es de suma importancia reflexionar qué propuesta de vida y qué valores están proponiendo estos videos, qué imaginarios están construyendo y qué modelos de afectividad, sociales y de género están asimilando los más pequeños como los aceptables y deseables.

\section{HIPÓTESIS Y METODOLOGÍA}

Una vez planteado el objetivo principal de nuestra labor investigativa, es necesario concretar una hipótesis de partida que marque la pauta y delimite nuestra labor investigativa. Para ello, el trabajo pretende analizar si, pese a los avances logrados y 
ya mencionados en materia de equidad de género, aún hoy existen agentes socializadores, como la música, y más concretamente la música infantil, que siguen promoviendo roles y estereotipos sexistas, trasladando a los más pequeños un modelo de sociedad machista, androcéntrico y heteronormativo, es decir, estructurado bajo la premisa de una "heterosexualidad obligatoria y la gestión social de las personas al ubicarlas en dos categorías binarias y supuestamente complementarias: hombres y mujeres" (Ventura, 2016, p. 933).

A partir de esta hipótesis que tratamos de verificar a lo largo del proceso investigativo, fijamos un modelo metodológico mixto que profundiza en una lectura analítica sustentada, además, en los datos estadísticos obtenidos del estudio. Para ello, se analizaron 30 canciones/videos desde una triple óptica:

1. Análisis con perspectiva de género de los roles protagónicos reflejados en las letras.

2. Representación de los modelos de feminidad y masculinidad en las letras y las imágenes de las canciones y videos seleccionados, profundizado en la representación del universo simbólico.

3. Estudio sobre la existencia de apuestas o modelos divergentes a los hegemónicos y tradicionales.

El estudio se llevó a cabo abordando ocho campos de análisis en los que se profundiza sobre los aspectos adelantados para la obtención de los datos estadísticos de cada uno de los tres canales seleccionados para nuestro estudio: El Reino Infantil, La granja de Zenón y Toy Cantando, los cuales cuentan con casi 40 millones de suscriptores. La elección de estos tres canales obedece a su repercusión y capacidad de permeabilización atendiendo al número de suscriptores y de visitas y visualizaciones de sus videos. Los tres canales citados son, en este sentido, los más exitosos de la plataforma YOUTUBE. Una vez seleccionados estos, procedimos a llevar a cabo una selección de las canciones/videos objeto de estudio, delimitando el campo de análisis a las 10 canciones/videos con mayores reproducciones de cada canal, obviando para ello videos que fueran recopilatorios, es decir, se analizaron únicamente canciones individuales y se desecharon videos, que estuvieran entre los 10 más reproducidos, que fueran un popurrí de canciones encadenadas.

En un primer momento, se barajó la posibilidad de delimitar el campo de análisis a videos y canciones donde los protagonistas fueran personas y no animales o seres inanimados con el objetivo de priorizar en la verificación de nuestra hipótesis y delimitar el análisis al estudio de los roles reproducidos a través de seres humanos, pero tras el análisis de las letras de las canciones y sus representación visual se concluyó que las canciones llevan a cabo un proceso de humanización de los personajes, otorgando a los animales/cosas protagonistas capacidades propias de humanos, tales como la reflexión, la formación de una familia, la opción del poliamor como forma de relación sentimental, la capacidad de estudiar una carrera universitaria... es decir, los niños y niñas identifican las acciones de los animales protagonistas con accionar de los seres humanos, por lo que finalmente se consideró oportuno y necesario analizar los videos sin la citada discriminación. Además, debemos destacar que todos los videos y personajes analizados son de ficción, es decir, los tres canales apuestan por videos de dibujos animados, algo que 
les diferencia de otros canales, como, por ejemplo, Cantajuegos (que cuenta con más de tres millones de suscriptores) donde son personas reales las que cantan (tres hombres y tres mujeres vestidos iguales), bailan e interpretan las letras de las canciones, muchas veces interactuando con niños y niñas.

Por último, los datos obtenidos desde este primer análisis cuantitativo fueron analizados desde una óptica cualitativa para ahondar en la verificación de nuestra hipótesis, profundizado, entre otros aspectos, en la representación simbólica de los personajes.

\section{DISCUSIÓN: DESARROLLO DE LA INVESTIGACIÓN}

Las canciones, como casi todas las expresiones culturales, se han consolidado históricamente como un fiel reflejo de los códigos y lenguajes morales de una sociedad, en especial las canciones populares. Asimismo, la música en la primera infancia juega un papel importante en el proceso educativo ya que desde los 18 meses, niños y niñas "internalizan sus esquemas sensoriomotores (relaciones de conducta) en forma de esquemas cognitivos (pensamiento)" por lo que adquiere una especial relevancia la influencia de la música en los primeros años de vida de una persona para su "evolución integral" (Ros, 2003, 197-198). Las canciones, a través de sus letras, y en su caso el componente visual de los videos, permiten analizar desde la estética dominante hasta los valores hegemónicos de una sociedad determinada en un momento histórico preciso, un hecho que también queda reflejado en la música infantil, entendiendo esta como aquella dirigida a un público cuyas edades oscilan entre los 0 y los 6 años (Fernández, 2006). Si bien es cierto que dentro de la música infantil existe una variada tipología atendiendo al fondo y a la forma de la misma (Lúdicas, para el desarrollo de habilidades, para dormir, didácticas...) todas comparten unas características formales basadas en letras divertidas y sencillas de aprender, ritmos atractivos y melodías simples que provocan empatía con su público. Junto a ello, la componente visual apuesta por colores llamativos, animales y/o personas como protagonistas que interactúan y muchas veces responden con sus gestos a las acciones de las letras. Como destaca la investigadora Pilar Aguilar (2015) "el relato audiovisual tiene una enorme capacidad para educar emociones, mapas afectivos, sentimientos e imaginarios" ( $p$. 25), por lo que resulta fundamental su análisis en el presente proyecto, complementando así la labor de estudio de las letras de las canciones.

\subsection{Roles protagónicos reflejados en las letras de las canciones y los videos}

Aunque no cabe duda de que en las últimas décadas se han conseguido importantes logros y avances en la trasformación de la sociedad y la superación de las desigualdades y discriminaciones por razones de género, aún persisten normas y conductas sociales que siguen perpetuando mandatos históricamente impuestos por el patriarcado, que ha marcado una "subordinación histórica de la mujer" conceptualizándola a partir del "cuerpo femenino" y reduciendo la identidad femenina a su "función reproductiva" (Montesinos, 2002, p. 19). Pese a que, como hemos adelantado, podríamos pensar que, al menor priori, los mandatos patriarcales ya han sido superados, analizando con perspectiva de género el accionar y los mensajes contenidos en los principales agentes socializadores podemos observar como estos 
siguen potenciando en mayor o menor medida estas normas patriarcales, incluyendo, a su vez, unos claros mandatos de qué es lo masculino y lo femenino. Por ello, es fundamental analizar el papel de agentes socializadores influyentes a la hora de perpetuar o deconstruir estos arquetipos sexista en la construcción de las "identidades", entendidas como simples "definiciones biológicas innatas" sino como "efecto de un proceso de socialización que da cuenta de la reproducción de un orden social y cultural” (Palacio; Valencia, 2001, p. 29).

La música se ha consolidado a lo largo de la historia como un agente socializador de suma importancia, capaz de plasmar e incluso fortalecer los valores y lenguajes morales (Cortina, 2007) de una sociedad determinada, a la vez que promover cambios y replantear la validez del sistema y sus principios. Este potencial transformador y/o promotor de valores se ha acentuado en las últimas décadas con motivo del auge tecnológico y la proliferación de nuevas plataformas digitales, las cuales han supuesto también un especial potencial para la música y las producciones enfocadas al público infantil. En este sentido, las historias que se desarrollan en las canciones infantiles suelen apostar por situaciones cómicas que son solucionadas de forma cómica y desenfadada y desenlaces positivos. El análisis desarrollado se ha centrado única y exclusivamente en el estudio de videos de canciones, es decir, se ha excluido del análisis juegos o videos educativos interactivos, así como conjuntos de canciones recopiladas en un mismo video. Es destacable que dos de los canales con más suscriptores, en este caso El Reino Infantil y La Granja de Zenón, comparten videos, es decir, el Reino Infantil incluye canciones que específicamente señala que son pertenecientes a la Gran de Zenón $y$, en otros casos, los tres canales analizados comparten entre sí las mismas canciones, pero con versiones muy distintas, como es el caso, por ejemplo, de la canción La Vaca Lola.

Uno de los objetivos de la investigación se centró en analizar tanto las letras de las canciones como su representación audiovisual en los videos seleccionados, aplicando para ello de forma transversal la perspectiva de género, y llevando a cabo, para ello, un primer análisis sobre los personajes protagónicos de las historias. A través de la unión entre la música y el texto, las canciones conforman tramas que después son reproducidas por los más pequeños casi de forma de automática durante años, sin pararnos a pensar que, en ocasiones, esas letras contienen una alta carga simbólica, estableciendo "una clara distinción" de un deber ser fundamentado en actitudes machistas, es decir, potenciando la diferenciación de roles entre "el papel del hombre y de la mujer" en la sociedad, a la vez que construyendo imaginarios que, quizás "de manera inconsciente" se convierten "en un impedimento para lograr la igualdad entre ambos género" (Berrocal; Gutiérrez, 2002, p. 188).

Durante el análisis desarrollado se evidenció que de forma mayoritaria el papel protagonista de las historias cantadas corresponde a hombres/varones, es decir, son ellos quienes marcan mayoritariamente las pautas de las tramas y subtramas y se sitúan como actores principales de las canciones/videos mientras que las mujeres/hembras, son relegadas en la mayoría de los casos bien a la invisibilización o bien a un papel secundario/dependiente del hombre. Analizando cada una de las canciones, cada uno de los 30 videos seleccionados, podemos observar que el $50 \%$ 
de los Personajes Principales son hombres/varones (15), mientras que sólo el 23\% de los papeles protagónicos (7) corresponden a mujeres/hembras (gráfica 1), reproduciendo, a su vez, una clara apuesta por la construcción social simbólica basada en el binarismo tradicional hombre/ varón frente a mujer/hembra.

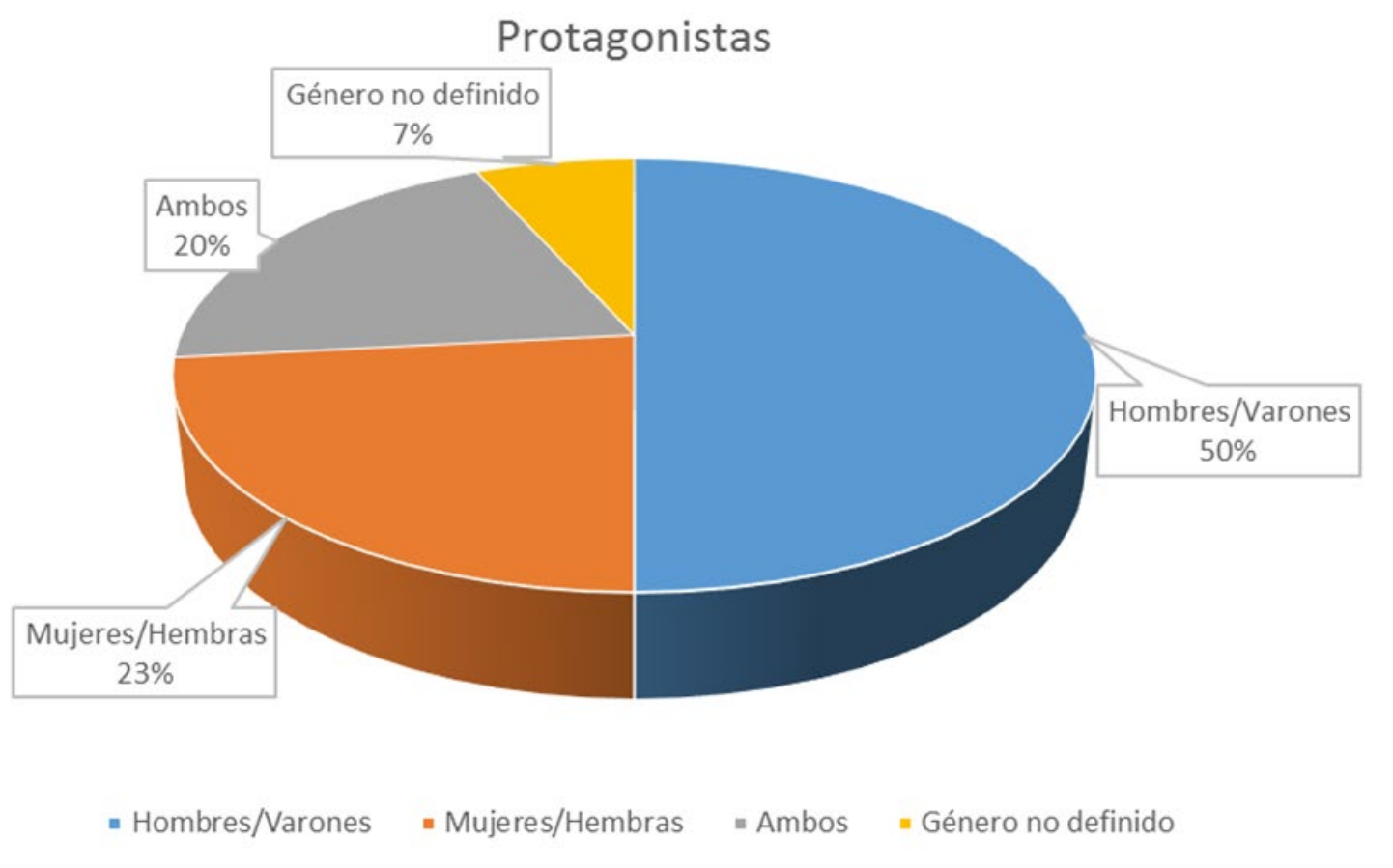

Gráfica 1: protagonistas de las historias de las canciones.

Fuente: elaboración propia.

Aplicando una óptica cualitativa al muestreo y centrando nuestro campo de análisis únicamente en las canciones/videos en las que aparecen mujeres en un papel destacado (gráfica 2), observamos una las representaciones simbólicas son de una importante valía, ya que el rol que se le atribuye de forma mayoritaria a las mujeres/hembras que intervienen en las tramas argumentales de los videos es el de "esposa, pareja, pretendida, objeto de deseo o cuidadora de un varón/hombre". De los 18 videos en los que sí aparece algún personaje femenino (siete como principal y once como secundario) observamos que en ocho $(41 \%)$ el rol de estas es supeditado a "mujer de, madre de, cuidadora de", como hemos señalado (mujer, esposa, pareja, pretendida, objeto de deseo o cuidadora) mientras que en seis ocasiones su papel es intrascendente (29\%). 


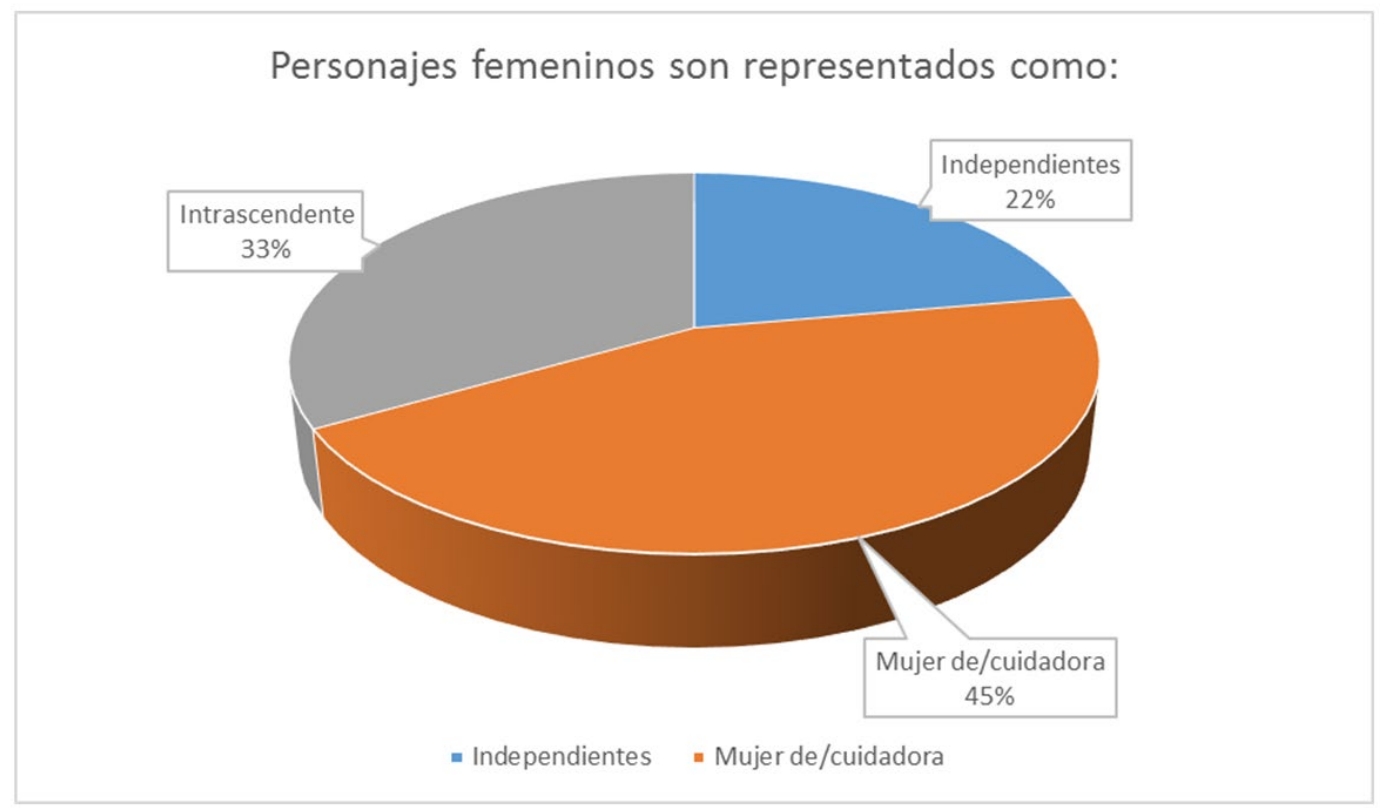

Gráfica 2: representación de la mujer cuando es protagonista.

Fuente: elaboración propia.

Desarrollando un análisis individualizado de cada uno de los tres canales analizados (gráficas 3, 4 y 5) observamos que las cifras presentan cambios aunque no de una forma significativa en este apartado y muestran unas tendencias bastante similares. Sin embargo, podemos observar que en todos los canales es superior la presencia de protagonistas masculinos. En el caso de El Reino Infantil el $50 \%$ de los personajes principales son representados por hombres/varones, una cifra que sube hasta el $60 \%$ en el caso de La granja de Zenón y baja al $40 \%$. En Toy Cantando. Sin embargo, es este último canal el que más mujeres/hembras muestra con papeles protagonistas, con un $30 \%$, frente al $20 \%$ de El Reino de Zenón y El Reino Infantil.

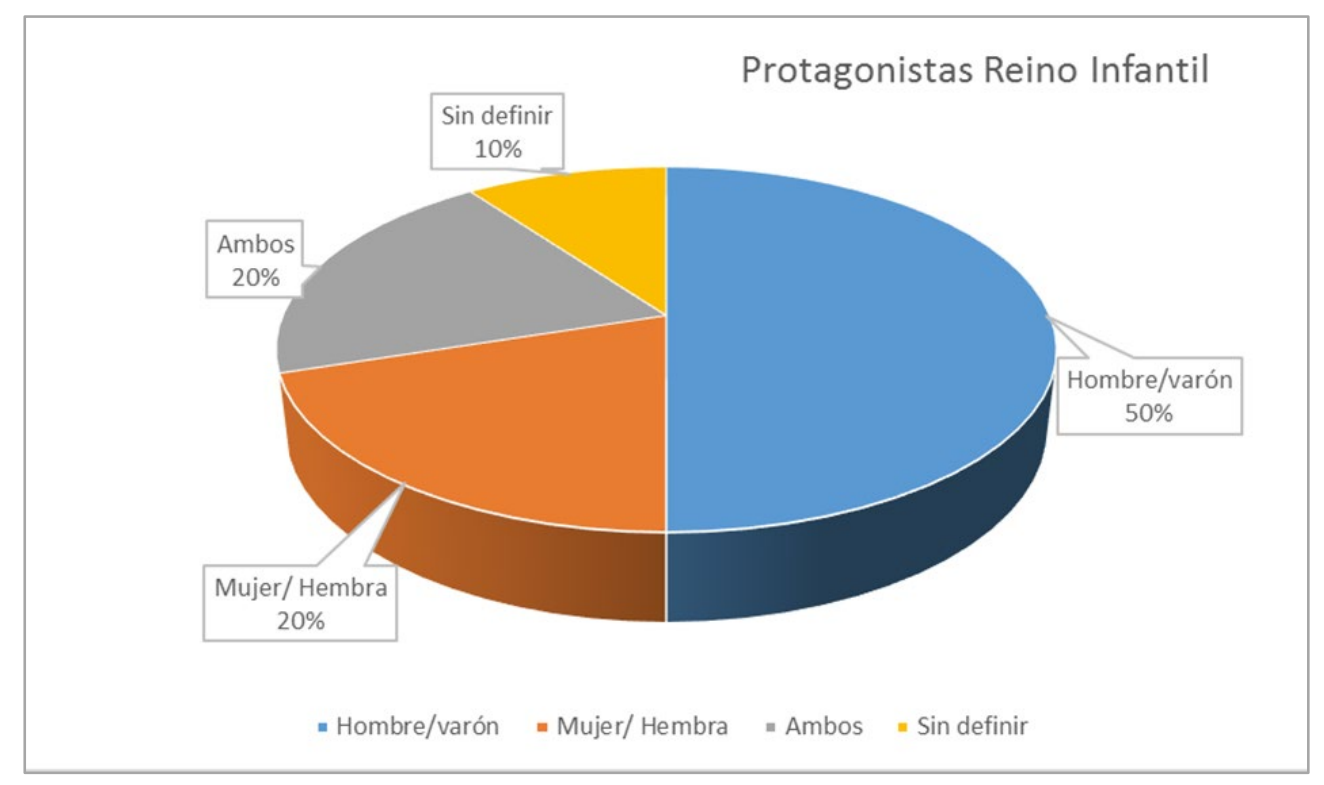

Gráfica 3: protagonistas de las historias de las canciones en El Reino Infantil. Fuente: elaboración propia. 


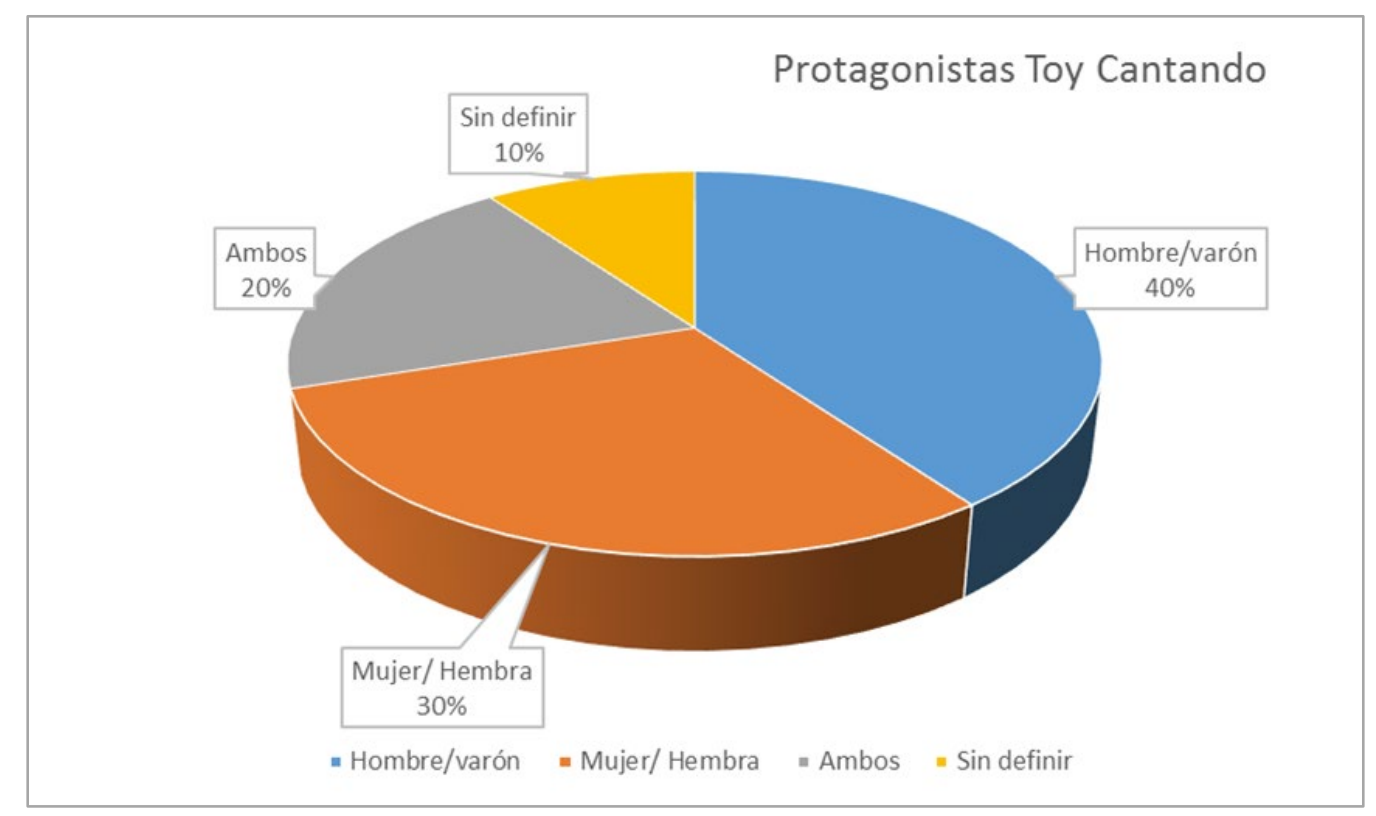

Gráfica 4: protagonistas de las historias de las canciones en Toy Cantando. Fuente: elaboración propia.

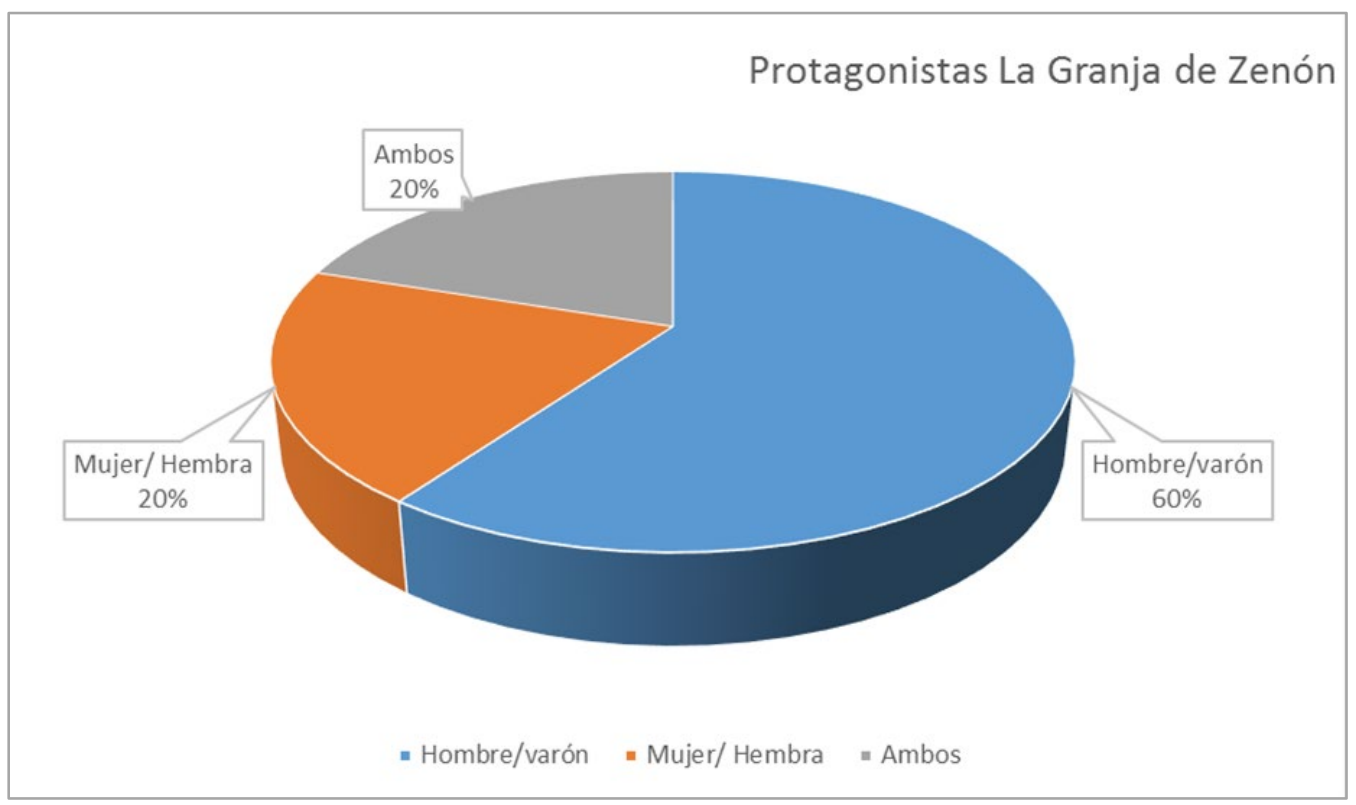

Gráfica 5: protagonistas de las historias de las canciones en La Granja de Zenón. Fuente: elaboración propia.

\subsection{Representación simbólica analizada con perspectiva de género}

Las representaciones tienen un papel relevante a la hora de construir o deconstruir modelos y pensamientos machistas, constituyéndose como "entidades en sí mismas", conformando "realidades mentales" y "construcciones psíquicas y materiales" que implican "dimensiones simbólicas y sociales" (Bruel, et al., 2013). Por ello, profundizando en el análisis de este campo desde una óptica cualitativa tras analizar tanto las letras como la representación audiovisual de las mismas en cada 
uno de los canales, diferenciamos tres rasgos que resultan especialmente llamativos en relación a la representación simbólica analizada desde una perspectiva de género:

1. La mujer/hembra representada como agente pasivo/secundario vista de la mirada androcéntrica del varón, el cual reivindica su masculinidad a través de la agresividad y la sexualidad dominante frente a la hembra, receptora en un sistema heteronormativo que llega, incluso, a reproducir prácticas relacionales cuanto menos peligrosas que normalizan el acoso sexual.

2. Hombre/varón representado como protector, intelectual y físicamente superior a la mujer/hembra, la cual se representa con roles de cuidados y hogareños, siendo, además, discurseada por el hombre.

3. Estereotipos de género sexistas en los universos simbólicos de los roles y modelos de vida.

\subsubsection{La mujer/hembra representada como agente pasivo/secundario y objeto en disputa/deseo de los varones en un universo androcéntrico}

Respecto a la primera característica destacada, podemos observar cómo esta se refleja en canciones/videos de los tres canales analizados. En el caso de El Reino Infantil destaca el hecho de que en tres de los diez videos analizados se otorga a la mujer/hembra un rol de agente pasivo y/o a merced/supeditada al hombre/varón, reduciendo, además, la finalidad de su existencia a esperar al macho (inteligente) maquillada, perfecta y dispuesta a sus deseos varoniles o, en otros, a ser protegida por éste; es decir, nos situamos ante letras y videos que nítidamente apuestan por un universo androcéntrico, un sistema en el cual el hombre/varón es la "medida de todas las cosas" (Varela, 2018, p. 158) y sobre el que gira el resto. Esta representación androcéntrica del mundo no es baladí ya que supone el inicio de una construcción intersubjetiva basada en representaciones sexistas de la vida que derivan en último término en la legitimación de la "violencia física y simbólica" (González, 2013, p. 493). Esta práctica es más explícita si cabe en la canción El gallo y la pata, la cual es la cuarta en número de reproducciones, contando con más de 600 millones de reproducciones. La canción narra una relación amorosa entre el gallo del corral y una "pata que nadaba en la laguna". El video comienza con el señor Gallo rodeado de cinco gallinas que bailan a su alrededor mientras él, remolón, se bambolea hacia un lado y el otro y cacarea. El cantante (hombre) narra cómo:

El gallo se enamoró perdidamente, de una pata que nadaba en la laguna, y ese gallo que era muy inteligente, a la pata el cantaba con la luna. Pero el pato que se había puesto celoso, se coló por el corral de las gallinas, y decía "este pato me las paga" y con todas las gallinas solito se quedó.

Ya la propia letra de la canción contiene numerosos e interesantes mensajes que ameritan un análisis pormenorizado. En tan solo 43 segundos, lo que parece a primera vista un video carente de trasfondo se transforma en un canal de transmisión de peligrosos modelos afectivos basados en la sumisión y la asimetría de género, apostando, además, por modelos de masculinidades basados en la agresividad y la posesión. 
Como analiza Ana De Miguel (2019) la construcción social de las identidades se inicia desde la primera infancia con un proceso de "socialización diferencial" ( $p .46)$ que en el caso de la identidad masculina, "toma los referentes establecidos por la cultura patriarcal" para "legitimar el sentido de la masculinidad articulándola con el ejercicio del poder" (Palacio; Valencia, 2001, pp. 73-74) y promoviendo modelos de varonías basados en la imposición, la violencia y la posesión, potenciando, a su vez la contraposición y la ruptura con el mundo femenino y todo lo que ello representa. En este sentido, la canción representa a la mujer/hembra como un ser pasivo, carente de voluntad a la espera de lo que decida su hombre/macho y lo ejemplifica desde lo verbal y desde su escenificación audiovisual. Ya desde el inicio, el gallo (masculino) se sitúa como epicentro de la trama y entorno a él se van configurando las acciones sucesivas, hasta tal punto que la propia canción reconoce que es el Gallo quien se enamora "perdidamente" de la pata que nada en la laguna, pero jamás se pregunta sobre la opinión de la pata, lo más que sabemos según avanza la canción es que ella, al final, "aprendió a cacarear". Es el protagonista varón quien decide, quien, como señala la canción, "es muy inteligente", algo que jamás se destaca ni en las gallinas ni en la pata, y quien cuenta y actúa sobre un agente pasivo y receptor que es, en este caso, la hembra, con un agravante más, ella, según la canción, tenía pareja: un pato, quien al enterarse de la posible infidelidad decide enfrentarse físicamente al gallo e ir al corral, donde se encuentra a solas con las gallinas y se queda con ellas como nuevo macho y epicentro de la granja. Es decir, la pata, pasa a ser un elemento en disputa por los machos, la cual no tiene ni voz ni voto; ellos deciden quién será su dueño y lo hacen mediante la agresividad, mientras las otras damnificadas, las gallinas, repiten el patrón, primero sin intervenir en las decisiones del gallo y segundo, aceptando sin rechistar la llegada del nuevo macho en forma de pato. Con un agravante más, finalmente, el Gallo se va con la pata pero, al menos por lo expuesto en el video, regresa más tarde al corral con cara de enfado y desafiante para enfrentarse al pato, momento en el que finaliza la canción, sin saber cómo acabó el enfrentamiento en ciernes.

Una historia similar, basada en este caso en los devaneos amorosos de un pingüino con un conjunto de gallinas, es la que se desarrolla en la canción El Pingüino y la Gallina, del canal La granja de Zenón. En esta ocasión, cuenta cómo:

Un pingüino alto y bonito nadando llegó del polo, se metió en un gallinero para no sentirse solo. Las gallinas que lo vieron, de frac y tan extranjero, abandonaron al gallo por la pinta del viajero. Que coqueteaba con una, que con la otra se paseaba, rara era la gallinita que por su amor no peleara, pero al fin de la historia todas al gallo volvieron porque le pingüino era frío, mucha pinta y poco fuego.

Tras observar que el foráneo no es fogoso, el video muestra como las gallinas vuelven a bailar al son del gallo, quien, además, recurre a la fuerza para echar al pingüino del corral en la parte final del video, uniendo de nuevo la masculinidad a la violencia y la agresividad. Nuevamente se promueven modelos basados en el binarismo hombre-mujer, por supuesto cimentados en una visión heteronormativa omnipresente e hipersexualizada, en los que, además, son los varones heterosexuales los que "organizan las relaciones" (Bustamante, 2013). 
Esta práctica de reducir lo femenino a acompañante o apéndice del personaje principal que es, a su vez, el atractivo e interesante de la historia, también se da en la canción Caballo verde (El Reino infantil), cuyo protagonista, un equino verde, "es tan inteligente que hasta usa lentes", hace piruetas, va en bicicleta, sabe hablar... un portento. Y como un satélite que orbita alrededor del protagonista aparece su novia, "una rubia muy coquetona" que se "pinta los labios rojos y es percherona". Esos son sus grandes atributos, ser rubia y pintarse los labios rojos.

La visión androcéntrica y de relaciones asimétricas también está presente en el canal Toy Cantando, el que se reproducen estos roles, aunque con distintos matices, en canciones como Pinocho, Juguemos en el bosque o En un Bosque de la China. Esta última es especialmente llamativa ya que nos situamos ante una canción popular, creada a mediados del siglo $X X$ y versionada para el público infantil desde hace más de 40 años, que ha sido escuchada y repetida por varias generaciones. Sin embargo, un análisis pausado de la letra devela un mensaje peligroso que deriva, además, en la normalización de unas relaciones de pareja tóxicas. La canción sitúa a una niña/joven asiática perdida en un bosque en el que es acosada tanto por la luna como por un niño/joven. La canción señala literalmente:

En un bosque de la China, la chinita se perdió, como yo andaba perdido nos encontramos los dos. Era de noche y la chinita tenía miedo, miedo tenía de nadar solita. Anduvo un rato y se sentó, junto a la china me senté yo... y yo que sí, y ella que no, y yo que sí y ella que no, y al rato fuimos de una opinión (...) bajo el cielo de la China, la chinita se sentó y la luna en ese instante indiscreta la besó.

La letra, ya de por sí cuanto menos digna de análisis, es además acompañada por un interesante contenido audiovisual que refuerza un mensaje que normaliza el acoso, mostrando como la niña/joven, ante la insistencia del varón, que se arrima a ella una y otra vez, se aleja repitiendo "que no" quiere nada, ante la persistencia y el acoso del varón que repite "que sí", "que sí", acercándose para tocarla, a lo que ella responde con reiteradas negativas, incluso alejándose, pero no es suficiente; además, la canción potencia el estereotipo, muy peligrosos entre los más jóvenes, de que "quien la persigue la consigue", o "si ella dice no, en realidad es que quiere decir sí", algo que, en la canción, sucede ya que, al menos a priori, parece que ella acaba cediendo y besa al insistente e incansable joven. Sin embargo, el momento álgido es cuando la luna, al verles juntos, baja a la tierra y besa a traición a la joven, acto que acaba provocando en llanto y la huida de ésta en un caso explícito de acoso que es banalizado pese a su gravedad.

\subsubsection{Hombre/varón protector, intelectual y físicamente superior a la mujer/hembra, reducida a labores de cuidados y hogareñas y discurseada por el hombre}

Otro de los aspectos a destacar por su presencia en numerosas canciones es la apuesta por tramas en las que el hombre/varón juega un rol de protector de la hembra, mostrando una cierta superioridad intelectual que valida tal papel y que, en numerosas ocasiones, relega a la mujer/hembra al ámbito de lo doméstico y a ser discurseada por el varón. La canción Cuidado con la Bomba Chita, ejemplifica esta realidad ya que, a pesar de que la protagonista, al menor a priori, es Chita 
(Mujer/Hembra) es el hombre varonil y protector representado por Tarzán, quien salva a la protagonista de "dos cazadores malos". Es interesante destacar el hecho de que a pesar de que es el personaje femenino el que da nombre al título $\mathrm{y}$, en principio, pudiéramos pensar que ella es la heroína de la canción, lo cierto es que, finalmente, la letra narra las peripecias y bondades del varón coprotagonista del video, el cual se esfuerza por proteger a Chita de una bomba que ponen unos "cazadores malos". La letra señala literalmente:

Venía Tarzán corriendo, del brazo de su monita, y dos cazadores malos, querían matar a Chita. Le pusieron una bomba donde la mona jugaba pero Chita se salvó pues Tarzán así el gritaba: Cuidado, cuidado, cuidado con la bomba Chita".

Como señalábamos esta relación asimétrica se fortalece con la representación de la figura masculina como protector, intelectual y físicamente superior a la mujer/hembra, la cual se representa con roles de cuidados y hogareños, siendo, además, discurseada por el hombre. Canciones como Pinocho (donde el doctor, un hombre sabio, logra con su "vieja ciencia" remendar el daño de Pinocho en el Hospital de los muñecos, mientras que la enfermera cuidadora y el hada protectora son representadas por mujeres) o Juguemos en el Bosque (donde los niños juegan mientras las niñas, con vestimentas rosadas, observan y aplauden las peripecias de estos) del portal Toy Cantando.

Incluso, cuando las protagonistas son mujeres estas pierden su papel como vertebradoras de la historia, sino que, como pasa en el caso de La Gallina Turuleca (La granja de Zenón) la cual es literalmente discurseada por el hombre que canta la canción, es decir, él va narrando los huevos que pone una gallina que, además, al contrario que los protagonistas masculinos, ni es bonita, ni es inteligente, ni sabe leer, hablar o montar en bicicleta, al contrario, la gallina, según la letra de la canción:

parece una sardina enlatada, tiene las patas de alambre porque pasa mucha hambre y la pobre está todita desplumada, pone huevos en la sala y también en la cocina, pero nunca los pone en corral (...) la Gallina Turuleca es un caso singular, la Gallina Turuleca está loca de verdad".

Ahondando en el análisis de los estereotipos de género basados en el universo simbólico, es importante destacar el hecho de que en numerosas ocasiones las mujeres son representadas como esposas-madres-cuidadoras. Como señalan Batthyány, Genta y Scavino (2017) la sociedad reproduce unos "mandatos de género que definen las expectativas y obligaciones" (p. 297) que históricamente han identificado a las mujeres con el ámbito doméstico y el papel de cuidadoras. Este factor no es, ni mucho menos, un hecho baladí sino que engloba toda una serie de mensajes que refuerzan las bases más anquilosadas del pensamiento machista, identificando lo femenino con "el ámbito de lo doméstico" quedando "enclaustradas en la esfera de lo privado" (De Miguel, 2017, p. 71). Esta concepción queda plasmada claramente en la canción Crocki Crocki (La Granja de Zenón) la cual narra la historia de un sapo que entra en una casa, anunciando que este:

se fue tras la muchachada, abuela dio de gritos porque estaba ya acostada, el sapo dio un salto y cayó sobre la almohada (...) salta salta en la almohada de la abuela, cuando el entró en el cuarto puso más leña la hoguera, mamá perdió la calma y corrió tras de sus huellas, el sapo salta salta sobre la peluca de ella". 
La mamá, representada a lo largo del video limpiando la casa, es la responsable del cuidado de los tres niños que aparecen en la canción (dos de ellos varones) quienes esperan juegan con el "travieso" sapito (varón) que desordena la casa y asusta a la abuela. El video reproduce nuevamente una conceptualización de la mujer estereotipada, asignándole "atributos naturales" a partir de su "función reproductiva" y, nuevamente, apostando por la dicotomía histórica que se "deriva de la fórmula mujer= madre" (Montesino, 2002, p. 9).

\subsubsection{Estereotipos de género basados en el universo simbólico}

La representación de la mujer/hembra en el ámbito doméstico, también de forma simbólica reproducida en canciones en las que los animales protagonistas son hembras, como por ejemplo en la canción La Gallina Turuleca, La vaca Lola o El pavo la pava, son siempre representadas en lo doméstico, en este caso, una casa o un corral o, como sucede en el caso de El pavo y la pava, como seres cuya misión y ambición en la vida es casarse con un varón. Esta canción, a pesar de su pretendido tono humorístico, contiene numerosos elementos que perpetúan roles y estereotipos sexistas, que limitan los deseos, proyectos y modelos de vida feliz de la mujer/hembra, enfocados en ser esposa de un varón. La canción comienza con los protagonistas (un pavo y una pava) ante el altar de la granja seguido de un rotundo grito de VIVA LOS NOVIOS. Acto seguido la imagen retrocede y vemos a los invitados, cinco gallinas que aplauden fervorosas y un gallo, con una botella y aspecto de ir gravemente embriagado, quien grita a duras penas un "qué vivan, qué vivan" antes de caer dormido fruto de la borrachera. Ya en el desarrollo de la trama, la Pava le pide al varón "Pavo vente pa mi nido (...) quiero un pavo por marido", a lo que él responde "yo soy pavo y no he dormido", de lo que se podría intuir que formó parte de la fiesta con el Gallo mostrado al inicio con un posible coma etílico. Mientras esto sucede, las gallinitas amigas de la pava, entre ellas Turuleca, bailan felices en el corral celebrando el evento, esperando que la novia lance su ramo, el cual cae en una de ellas, Turuleca, que tras recibirlo mira sorprendida al amigo del Gallo embriagado, quien observa con pavor la escena, entendiendo que debe casarse con la gallina receptora del ramo; pero por si había alguna duda, la escena y la canción continúan con bailes de todos, incluido el gallo, que parece tratar de disipar de este modo las intenciones de la gallina, quien lejos de desistir se lanza sobre él de forma desesperada para después mirar con cara de terror al pavo-cura que se acerca con la intención de casarles.

\subsection{Modelos divergentes}

A pesar de que los videos analizados muestran numerosos aspectos para la reflexión, revisión y modificación, también es cierto que hay lecturas que nos aportan una mirada positiva en relación a modelos de masculinidades que pueden convertirse en referentes para seguir avanzando en este camino. Tal y como señala el investigador Ritxar Bacete (2019) los mandatos de género son también "una cárcel invisible" para los hombres (p. 56) que deben ser enfrentados con propuestas de modelos de masculinidades más "democráticos". En este sentido, hemos divido la deserción de estos capítulos en torno a dos ejes argumentales:

1. Paternidades activas y responsables.

2. Afectividades y representaciones masculinas diversas. 


\subsubsection{Paternidades activas y responsables}

Sobre el primer eje temático, destacamos sobre todas las canciones la titulada "Johny Johnny, sí papá", del canal Toy Cantando, en la cual vemos como el papá de Johny, un bebé amante de las golosinas, se queda en casa al cuidado de su pequeño; después de que Johny le dice a su padre que tiene hambre, este último se apresura a preparar un guisado saludable a base de zanahorias y verduras que él mismo cocina. Es decir, es la figura paterna la que asume el cuidado y la alimentación de su hijo, algo inaudito en el resto de videos, lo que rompe con los modelos tradicionales y apuesta por un visibilizar el rol hombre-padre; además lo hace con un papel activo, es decir, cuida a su hijo, prepara la comida y cuando observa que Johny está comiendo dulces se lo recrimina.

Para finalmente obligar al bebé a expulsar las golosinas de su boca y comer el potaje vegetal preparado por el padre. El pequeño Johny se enfada con su padre por sus negativas y se niega a comer alimentación saludable, pero finalmente accede y come sonriente una manzana con su padre, quien acto seguido se dirige de nuevo a la cocina para lavar los platos y vasos ya usados.

\subsubsection{Afectividades y representaciones masculinas diversas}

También relacionado con la promoción de nuevos modelos de masculinidades, observamos apuestas que rompen con la unión tradicional de los hombres/varones con la agresividad. Si bien es cierto que prácticamente todos los videos abogan por un sistema basado en la heteronormatividad y "binarismos de género" (PÉREZ, 2007), hay algunos aspectos positivos en relación a la asunción de las masculinidades. Un ejemplo de ellos es la canción "Si tú tienes muchas ganas de aplaudir" del canal Toy Cantando. Aunque los protagonistas del video son tres personajes masculinos, Pinocho, el muñeco de cartón Pim Pom y el payaso Plin Plin, muestran actitudes cariñosas, sistemáticamente reducidas al ámbito femenino. En este caso, son tres varones los que son capaces de reír, gritar e incluso llorar, mostrando, además, una inhabitual afectividad entre ellos, abrazándose y haciéndose cosquillas mutuas. Esta representación viene además acompañada por una puesta en escena que potencia nuevos modelos de masculinidades, opciones diversas y divergentes que van más allá de los roles y estereotipos tradicionales. En este sentido, el Payaso Plim Plim es representado con pelo largo y rubio, maquillado, algo por otro lado habitual dada su naturaleza circense, pero con una camiseta colorida, que da la sensación de ser un arcoíris, y con un peculiar bombín rojo adornado por una llamativa flor amarilla, algo que también ocurre en Pinocho; este último apuesta por una vestimenta marcada por los complementos, con un sombrero rojo que muestra lo que parece una pluma verde en su parte frontal, y una elegante camisa amarillenta, tirantes negros y corbata naranja. Es cierto que los personajes masculinos en un porcentaje importante superan el estereotipo de que ser representados con el color azul, y es habitual ver a estos con vestimentas blancas e incluso coloridas, algo que no se da en el caso de las mujeres/niñas/hembras, las cuales aún son representadas en un porcentaje importante con colores rosas y/o complementos rosados o morados, como ocurre en el video Mi carita redondita del canal Toy cantando. 
También relacionado con la promoción de nuevos modelos de masculinidades, observamos apuestas algo más sutiles desde lo simbólico, pero también importantes y reseñables en el estudio. En este sentido, destacamos la canción/video titulada "Patitos cua cua cua" de El Reino Infantil, donde se narra la historia de cinco patitos que pasean juntos, mueven la colita, las patitas, las alitas y dan una vueltita, antes de ir a nadas juntos. Los patitos, son representados además de forma cariñosa y afectiva, en ocasiones, incluso con fondos rosado y mostrando abiertamente su cariño, juntando sus rostros y descansando juntos.

\section{CONCLUSIONES}

Una vez realizada la labor analítica e investigativa, podemos concluir que, tal y como planteábamos en la hipótesis de partida, existen en la música infantil analizada representaciones y letras que siguen promoviendo roles y estereotipos sexistas, trasladando a los más pequeños un modelo de sociedad machista, androcéntrico y heteronormativo. Pese a los avances logrados y ya mencionados en materia de equidad de género, aún vemos como el machismo, el androcentrismo y los modelos marcados por una masculinidad cimentada en el control y la agresividad siguen perpetuándose a través de agentes socializadores tan importantes como, en este caso, la música infantil.

El estudio desarrollado evidencia que a pesar de que en un primer momento pudiéramos pensar que se han cambiado los patrones hegemónicos y avanzados hacia letras e historias que reflejan una realidad más equitativa y libre de estereotipos de género, la realidad demuestra que:

1. Los papeles protagonistas reflejados en las letras de las canciones y los videos son mayoritariamente acaparados por personajes masculinos.

2. Los personajes femeninos de forma minoritaria son representados por mujeres/hembras autónomas, sino que de forma mayoritaria juegan un rol limitado a ser la "mujer de, la madre de o la cuidadora de" u objeto de deseo o en disputa por parte de los varones/machos.

3. El ámbito de lo doméstico y la crianza de los más pequeños es aún una labor destinada a las mujeres/hembras, mientras que lo público es en gran medida acaparado por los hombres/varones.

4. Persisten los modelos de masculinidad basados en la agresividad y la posesión, donde el varón debe ser quien controle a la hembra o las hembras, que se convierten en objeto de disputa entre machos.

5. Las masculinidades tóxicas son normalizadas en diversas ocasiones mediante la banalización del acoso sexual y la trivialización del alcoholismo, algo "permitido" y asociado a la "naturaliza" masculina.

6. Aunque son escasos los ejemplos que abogan por mostrar nuevas formas de relación y valores que potencien un cambio social en pro de la equidad y la diversidad, existen ejemplos que dejan paso a nuevos modelos de masculinidad, paternidad responsable y empoderamiento e independencia de las mujeres, aunque, insistimos en este punto, son muy minoritarios los ejemplos.

Los diversos canales de comunicación, en su sentido más amplio, tienen una enorme responsabilidad y un papel destacado en los procesos de socialización de 
los más jóvenes, muy especialmente entre los pequeños, por ello es fundamental abogar por modelo que aboguen por formatos y productos diseñados con sensibilidad de género, en los que se analicen y estudien de forma pormenorizada los mensajes y patrones promovidos y reproducidos. Esta labor debe, a su vez, ser llevada a cabo desde una doble perspectiva consumido/emisor, ya que los educadores juegan un papel fundamental en la crianza y la consolidación de labores e imaginarios. A su vez es necesario abogar por la formación con perspectiva de género de los futuros profesionales, adquiriendo una capacidad crítica y analítica que prevenga sobre la reproducción de roles o estereotipos sexistas en canciones/videos destinados al público infantil. Solo desde la formación podremos cambiar de forma radical mensajes sexistas y avanzar hacia productos y propuestas audiovisuales que potencien sociedades y generaciones más libres, igualitarias, diversas y, en definitiva, democráticas.

\section{REFERENCIAS}

Aguilar, P. (2015). La ficción audiovisual como instrumento de educación sentimental en la modernidad. En HERNANDO, A. (Ed.) Mujeres, hombres, poder. Subjetividades en conflicto (pp. 25-54). Madrid: Traficantes de sueños.

Bacete, R. (2019). Nuevos hombres buenos. Las masculinidades en la era del feminismo. España: Ediciones Península.

Batthyány, K., Genta, N., Scavino, S. (2017). Análisis de género de las estrategias de cuidado infantil en Uruguay. Cuadernos de Pesquisa, 47(163), 292-319.

Berrocal, E., Gutiérrez, J. (2002). Música y género: Análisis de una muestra de canciones populares. Comunicar, Revista científica de Comunicación y Educación, 18, 187-190.

Bruel, T., Scarparo, H.; Reis, A.;, Calvo, J., Herranz, S. y Blanco, A. (2013). Estudio psicosocial sobre las representaciones sociales de género. Revista Diversitas perspectivas en psicología, 9(2), 243-255.

Bustamante, W. A. (2013). Masculinidades y homofobia. El control de la sexualidad del varón en la construcción del Estado colombiano. Sociedad y Economía, 24, 159-182.

Byung-Chul, H. (2017). La expulsión de lo distinto. España: Herder.

Coleto, N. (2015). La canción popular infantil en la educación escolar: los roles de género asignados [Trabajo Fin de Grado]. Facultat de Belles Arts de Sant Carles. Universitat de Politécnica de Valencia.

Cortina, A. (2017). Ética de la Razón Cordial: Educar en la Ciudadanía Para el Siglo $X X I$. España: Ediciones Nobel.

De Miguel, A. (2019). Neoliberalismo sexual. El mito de la libre elección. España: Ediciones Cátedra. 
Fernández, A. M. (2006). Género y canción infantil. Política y Cultura, 26, 35-68.

González, A. (2013). Los conceptos de patriarcado y androcentrismo en el estudio sociológico y antropológico de las sociedades de mayoría musulmana. Papers. Revista de Sociología, 98(3), 489-504.

Lamas, M. (2007) Género, desarrollo y feminismo en América Latina. Pensamiento Iberoamericano, 3(7), 133-152.

Marañón, I. (2017). Educar en el feminismo. España: Plataforma Editorial.

Martínez, N. y Colarte, A. (2013). La música y el enfoque de género en niños y niñas. Revista Cubana de Enfermería, 29(1), 5-17.

Montaño, D. (22-02-2019). YouTube kids, el "chupete electrónico" de moda. Diario El País. Recuperado de https://elpais.bo/youtube-kids-el-chupete-electronico-de$\underline{\text { modal }}$

Montesinos, R. (2002). Las rutas de la masculinidad: Ensayos sobre el cambio cultural y el mundo moderno". México: BIP. Biblioteca Iberoamericana de Pensamiento.

Palacio, M. C. y Valencia A. J. (2001). La identidad masculina: Un mundo de inclusiones y exclusiones. Colombia: Editorial Universidad de Caldas. Colección Ciencias Jurídicas y Sociales.

Pérez, N. (2007). A teoria queer e os intersex: Experiências invisíveis em corpos desfeitos, Cadernos Pagu, 28(1), 149-174.

Ros, M. (2003). La música en la educación infantil: Estrategias cognitivo-musicales. Ensayos, Revista de la Facultad de Educación de Albacete, 18, 197.

Tajahuerce, I. (2018). La formación con perspectiva de género en las universidades: La prevención de la violencia contra las mujeres a través de la formación. En: Tajahuerce, I.; Ramírez, E. La intervención en violencia de género desde diversos ámbitos. España: Editorial Dykinson.

Ventura, R. (2018). Tendencias de investigación sobre la heteronormatividad en los medios de comunicación. Opción, 32(10), 932-952.

\section{AUTOR:}

Doctor en Periodismo por la Universidad Complutense de Madrid. Profesor Investigador de la Facultad de Comunicación de la Universidad de Medellín jiuarez@udem.edu.co

Orcid ID: http://orcid.org/0000-0001-9441-8229 